Retirement from sport

\section{They think it's all over, but it may not be!}

\section{M Cockerill}

\section{Athletes of necessity retire early and often require help adjusting to their new life}

${ }^{\mathrm{t}}$ is evident that anyone required to perform at a high level in sport or other physically demanding occupation has a limited number of years before demands made on the body begin to take their toll, sometimes accompanied by difficulties of a psychological nature. Although there may be a good deal of informal support from family, friends, and perhaps even other athletes who have retired, in some sports there remain few initiatives devised specifically for those approaching the end of an athletic career. The issues raised and observations made in this article are based on selected research studies and also interviews with an elite amateur swimmer and a professional footballer. The former regularly devoted upwards of 25 hours a week to training and competition. In most instances the elite amateur has somehow to organise sport around a job, often full time, or study for academic and professional qualifications.

True, a few sports endeavour to assist retiring athletes in looking to the future, but they tend to be variable in both extent and content. A few professional associations-for example, the Professional Footballers' Association and the Jockeys' Association of Great Britain-operate as a catalyst to facilitate the transition process for their members, and both have proved successful in this endeavour. Some athletes make a seamless transition, whereas others struggle to adapt and are perhaps too proud to ask for help. After all, they may have been the focus of adulation for several years, and to realise that in the prime of life it is time to close the door on what you are best at is difficult to accept.

\section{WHY RETIRE?}

There are probably four principal reasons for an athlete leaving sport: personal choice, age, injury, and deselection. Only the first of these, when the individual has planned for the day when it is time to change direction, is normally acceptable to the athlete. Chronic injuries, and occasionally one that is sufficiently severe to prevent further participation, are common, and, with age, both intensity of treatment and recovery time tend to increase to the extent that more time may be spent in rehabilitation than participation. Despite the advantages of competitive experience, there comes a time when it is not possible to be involved at the level once enjoyed and it becomes clear that physical attributes are on the wane. The ageing process impinges, and most athletes recognise that their participation at an elite level is on the wane. There are some, of course, who continue to take part at a lower level, although it can sometimes be difficult for them to explain why. If they are content to keep playing principally for enjoyment, that should be encouraged, but some continue as the quality of their performance deteriorates and they become frustrated, and sometimes angry and bitter. Those athletes may have unfulfilled ambitions and objectives as players, while failing to recognise and fully enjoy the successes they have experienced in the past. Although these are broad categories, all retiring athletes have personal reasons for leaving competitive sport, and it would be unwise to suggest that each one fits nicely into one category or another. Some are able to remain involved in a coaching or administrative capacity, but for the majority it means changing direction and developing a new career.

\section{SOME PROCEDURES FOR ASSISTING THE RETIRING ATHLETE}

It is interesting that by the age of 35 , elite amateur and professional athletes, with a few exceptions, are more or less reaching the end of high level competitive sport. This reflects about 17 years of serious competition. After a further 17 years they will be just 52 years old; in other words, they have not reached normal retiring age. Thus, at 35 they are less than half way through a normal working life!

Two organisations have been mentioned that offer career guidance for professional sportsmen and women, but much more could be done. There is plenty of informal advice available from former athletes, and their guidance would be highly valuable to those still performing. These sources include not only ex-athletes who have developed a second, high profile career in the media, business, or professions, but also those whose change of direction has been at a relatively low level, yet rewarding nonetheless. The principal difficulty is matching the two groups-that is, ex-athletes who are prepared to advise and those who would benefit from that guidance.

Cockerill and Tribe ${ }^{1}$ referred to The British Psychological Society's statement that the role of the counselling psychologist is "to help people to improve their sense of well being, alleviate their distress, resolve their crises and increase their ability to solve problems and make decisions for themselves." Such a definition encapsulates the support that would benefit almost anyone approaching the end of an athletic career. There is clearly a need for guidance before, during, and after transition in the form of identifying existing skills that might transfer to a positive career change, facilitating the acquisition of new skills, and also building a database of people who might promote the athlete in a new venture. Support is also important should the change prove to be so stressful that there is a possibility of the athlete failing to cope adequately. For example, elite performers often have their lives within sport structured and organised by others, whereas outside of training and competition they may have much more "free" time than someone with a full time job. Hence, it can be difficult to manage time effectively when there is no one to arrange a daily programme for you and when much more personal responsibility has to be born than hitherto.

\section{"One of the most effective proce- dures for helping athletes around the time of transition is mentoring"}

Helping, according to Ray et $a l,{ }^{2}$ is not random behaviour; it is an act that someone performs in order to be of benefit to another. However, it cannot be assumed that anyone is able to help just because both parties are, for example, from the same sport. A prerequisite for a successful outcome is that, for whatever reason, there is empathy between helper and athlete, with the former wishing to assist and the latter being prepared to accept that support. One of the most effective procedures for helping athletes around the time of transition is mentoring, namely the enhancement of strengths and questioning reasons for behaviour that may 
be contrary to positive personal development. A mentor acts as a "sounding board" and, within a trusting relationship, counsels, supports, and guides a protégé. ${ }^{3}$ For example, Jackson, et $a l^{4}$ emphasised the value of mentoring for gold medal winning Olympians, and Lavallee $e t ~ a l^{5}$ used both qualitative and quantitative methods to explore the efficacy of mentoring among Olympic track and field athletes at the time of retirement from competition and subsequently. Although they cautioned that terms such as mentoring and counselling do not appear to be synonymous with the assertive, extravert, and ambitious image of the successful athlete, the provision of such a service, perhaps subsumed under a different name, can facilitate the transition from athlete to ex-athlete.

Finally, there remains the perennial question of whether to use psychometric testing as a diagnostic tool with athletes. A recent report by Sappal ${ }^{6}$ has shown that such procedures are used not only as recruitment tools within assessment centres, but increasingly for development purposes. Indeed, over the past two years, six times Champions' League winners AC Milan have been using an occupational personality questionnaire for both player selection and their development within the club. Given that the procedure is generating useful data in Italy, it follows that it may also be a valuable tool to facilitate the transition of their players, especially those who do not become financially independent at the end of their playing careers. Grimley ${ }^{7}$ has suggested that psychometrics may be a useful adjunct to the skills of a good coach or counsellor, whereby responses can facilitate the development of a client's explanation of their situation, although a psychometric test cannot replace rapport between psychologist and client. As the following brief case studies will emphasise, the end of a career as an elite performer may have a positive outcome, but it can also prove difficult.

\section{CASE STUDIES}

Two athletes were interviewed: a female swimmer and a male footballer. Both had retired from choice and were pursuing new directions in a full time capacity.

The professional footballer was in his mid-30s, a striker, and he had played at a high level in the United Kingdom and abroad. He has subsequently trained as a health and fitness consultant and started his own business, which he describes as a "life challenge." This form of work began to appeal to him following positive feedback from other footballers whom he had helped with

injury rehabilitation on occasions when he was also injured. He reported that injured players were too often left to their own devices and felt that personal attention was vital to rapid rehabilitation. Indeed, it was the increasing amount of time spent injured that eventually determined his decision to retire from the game.

His change of career had been exciting, and a normal working day of up to 12 hours had left him little time to miss football. Despite stating that he had "never been a planner", he spent time speaking with "trusted professionals" before seeking a qualification that led to, as he put it, "credibility." He does not enjoy the long hours, but so far everything is progressing better than expected and after a year he is able to employ full time staff.

\begin{abstract}
"Most professional athletes find it necessary to continue working after sport, and it is important that a new career is chosen carefully and is not merely a means to earn a living"
\end{abstract}

He believes that he continued playing for too long and felt it had been unwise to drop down divisions, where skill levels were lower and made him frustrated. His advice to other players was to make some specific decisions about the future by the age of 30 . He said that because "everything in football is done for you", it is especially important to develop what he referred to as "life skills." Most professional athletes find it necessary to continue working after sport, and it is important that a new career is chosen carefully and is not merely a means to earn a living.

The swimmer was in her early 20 s and managed to balance her life as an international athlete with that of a full time student, although sometimes with difficulty because of frequent periods of time spent competing abroad. She decided to retire from international competition and spend a year away from her degree studies in the United Kingdom to develop her language skills at a foreign university. The transition was more difficult than she had expected. It took up to four months for her to adjust and to realise that there was "life after training." Interestingly, her "new life" of going out in the evening without worrying about having to train at 5 am the next day was also difficult to adjust to. She had believed that planning for a year at an overseas university would accommodate her retirement from swimming. This was not the case, because freedom from intensive training was compounded by life in a foreign country, rather than being a fulfilling substitute for swimming. These two dramatic changes in her life had made the first few weeks difficult. Interestingly, the benefits of having free time, not waking up in pain from training, and not being permanently tired were matched, and sometimes outweighed, by the deficits.

\section{"It had been suggested that retire- ment from competition could be similar to divorce, as everything changes"}

She was concerned by the lack of structure to her new life. Whereas, previously, goals had been set from one competition to the next, losing her athlete's fitness proved problematic and, at first, she isolated herself from swimming friends and former coaches. Overall, she emphasised the importance of being prepared for a major change in lifestyle after retiring from sport. It had been suggested that retirement from competition could be similar to divorce, as "everything changes." Her advice to athletes in a similar situation was to learn how others had coped and to have an understanding family and friends for support.

To remain concise, it has been possible to reflect on the retirement perceptions of just two athletes. However, it may be concluded that planning for retirement from sport by professional and elite amateur athletes is a prerequisite to a successful future and, even then, it is possible that there will be surprises, both positive and negative. Although life may become neither better nor worse, it will almost certainly be very different and unlikely to be just as predicted. In other words, expect the unexpected! For example, a loss of identity is sometimes associated with transition, and the swimmer may have experienced this more than the footballer. Paradoxically, it is a comment from a footballer reported by Fortunato and Marchant ${ }^{8}$ that illustrates this sense of perceived abandonment. "When the club decides they no longer need you, they just don't want to know you; in fact, no one wants to know you." Fortunately, this may not happen often, but sometimes it does.

There are many issues for athletes, coaches, family, and friends to consider, but both research and anecdotal evidence point to the following key aspects:

- although there may be some similarities between different sports, there are probably many more differences, even within a given sport;

- plan for the time when your body says "That's enough" and you are then able to move on to something different, yet fulfilling, in life; 
- recruit former performers to share their experiences and support impending retirees as mentors;

- endeavour to develop new skills and to utilise transferable skills from sport;

- realise that because life will be different, the nature of close personal relationships may also change and they need to be worked at;

- recognise your successes as an athlete and move on to the next stage in life with a sense of fulfilment, rather than animosity and regret;

- understand that attaining personal satisfaction after leaving sport may take longer than expected;

- feel able to let go and be detached from your sport during transition;
- begin to identify yourself as, for example, a business person, rather than an ex-athlete;

- retire happy, perhaps the most important of all.

Br J Sports Med 2005;39:880-882.

doi: 10.1136/bjsm.2004.016642

Correspondence to: I M Cockerill, School of Medicine, University of Birmingham,

Birmingham, UK; iancockerill@

blueyonder.co.uk

Competing interests: none declared

\section{REFERENCES}

1 Cockerill IM, Tribe R. Counselling considerations in sport and exercise. In: Counselling in sport and exercise contexts. London: The British Psychological Society, Sport and Exercise Psychology Section, 2002.
2 Ray R, Terrell T, Hough D. The role of the sports medicine professional in counselling athletes. In Ray R, Wiese-Bjornstal DM, eds. Counselling in sports medicine. Champaign, IL: Human Kinetics, 1999:3-20.

3 Hardy CJ. Nurturing our future through effective mentoring: developing roots as well as wings. Journal of Applied Sport Psychology 1994;6:196-204.

4 Jackson S, Mayocchi L, Dover J. Life affer winning gold. II. Coping with changes as an Olympic gold medallist. Sport Psychology 1998; 12:137-55.

5 Lavallee D, Nesti M, Borkoles E, et al. Approaches to counselling athletes in transition. In: Lavallee D, Wylleman P, eds. Career transitions in sport: international perspectives. Morgantown, WV: Fitness Information Technology, 2002:111-30.

6 Sappal P. Top scorers. People Management 2005; 11:38-40.

7 Grimley B. Hard science in a soft world: a personal view. Counselling Psychology Review 2004;19:41-4.

8 Fortunato V, Marchant D. Forced retirement from elite football in Australia. Journal of Personal and Interpersonal Loss 1999;4:269-80.

\section{Olympics: who will survive?}

\section{P J Hamlyn, Z L Hudson}

\section{The health and social benefits of the Olympic Games to the general population are doubiful}

E ive cities were in pursuit of the 2012 Olympics. At the heart of each application was the bid document, which has crucial chapters on health and the Game's legacy. The Evaluation Committee of the International Olympic Committee (IOC) visited each city and interrogated their medical advisors, one of the current authors included, on every detail of the proposed health provisions.

With regard to the legacy, it is clear that the IOC's increasing concern is to develop the benefits left by the staging of this elite, mass spectator, sporting event. A legacy of health gain is at the centre of many of the bids, although to generate one is not as straight forward as it might at first appear. The health equation of an Olympic games is by no means simple. Profound effects are felt by the communities in which mass events are staged, as well as by the populations viewing them, and these may not all be beneficial.

The benefits for non-participants may derive in two ways.

Populations viewing an event may be inspired to exercise. In a poll of nearly 900 adults, 26\% stated that they had been inspired by British medal winning performances at the Olympic Games in Athens to play more sport, or to become more actively involved in sport in the future. ${ }^{1}$ However, good data on how often these intentions result in lasting action remain wanting.

The link to a specific sport may be direct. After the British Olympic success in curling, the sales of related equipment escalated substantially. The consequent exercise will have brought measurable health gain to Scotland, a black spot for deaths from stroke and heart attack. If only its population exercised, cases could fall by over a third-no drugs, angioplasty, or bypass can offer this scale of gain.

Sporting injury may in part negate the beneficial effect, as perhaps could be said of the upsurge in boxing following Amir Khan's Athens success. In general, it might be suggested that exercise improves health whereas sport may pose a risk to it, although at least here the health equation is simple. Overall gain equals the benefits of exercise minus the injuries from the sport participated in.

Clearly, mitigation of the negative impact of sports injury may derive from improving the availability of sports medicine services. For some nations there is certainly considerable scope. Whilst it has been estimated that $10 \%$ of all injuries treated at hospitals derive from sports, the British National Health Service currently has no sports medicine provision. The speciality was only recognised to coincide with the IOC Evaluation Committee's inspection in February 2005 and the first trainee is yet to be appointed. If there is to be a net gain to national health the speciality must have trained and appointed adequate numbers ahead of the surge in demand 2012 will bring. This stands whether or not the Games' organisers strive to amplify the natural surge by positive measures to promote wider sports participation as a means of delivering the promised legacy. If the NHS sports medicine provision comes after the event a legacy of disability from poorly managed sporting injuries will loom.

It is likely that a four year training programme will be agreed with the first recruitment in 2006. If just two hundred sports doctors were viewed as sufficient to meet the national demand by 2012 , the deaneries will need to be given the funds for around one hundred posts until then, though numbers could be substantially reduced thereafter. These numbers, or anything like them, will require the incorporation of the private sector in training rations as well as the funding of posts overseas. The 2012 London Olympics will be staged all over the country and will stimulate sporting participation more than any other event in Britain's history. To host the Games without a nationwide sport and exercise medicine service already established would be as to use an activated virus as a vaccine.

To maximise health gain, an event should be portrayed in a way that stimulates therapeutic exercise more than potentially injurious sport. For some nations there is certainly considerable scope. Only $32 \%$ of adults in England take 30 minutes of moderate exercise five times a week, a recommended minimum, compared with $57 \%$ of Australians and an exceptional $70 \%$ of Finns. ${ }^{2}$ The health 
benefits for the British population from an increased level of exercise ${ }^{3}$ would far outstrip anything that could be achieved for them by other means, including reducing obesity, cutting smoking, better cancer and blood pressure screening, healthcare planning, or health service resourcing.

Depending on the event and its viewing figures, there is a potential to encourage exercise on a global scale. For the health of advanced nations, it would be the equivalent of supplying safe drinking water to the struggling world. The target audience of such a scheme, the classical TV gazing couch potato, is reliably available as the viewer. Our current failure to link the viewing of mass spectator sport to a widespread uptake of regular exercise is possibly the most costly failure in our strategy to reduce disease in the developed world.

In the context of spectacular events such as World Cup Football, Commonwealth and Olympic Games, benefits may also accrue from inward investment in the communities staging the event. This lay behind Rio's attempt and was at the heart of London's, with the aim of changing a large tract of poor East London. New transport systems, sporting venues, hotels, living accommodation, hospitals, employment, and business opportunities will all result. Each is directly associated with improved community health-unemployed people in poor housing die young.

However, for advanced nations, there is no clear evidence of this association being reversed by placing the same communities in work and better housing. There is a danger too of gentrification, simply displacing local poor communities. Long term local financial liabilities also need to be factored in. Montreal's population is thought to have suffered financially for well over two decades after their 1976 games.

Sponsorship of sport by companies selling unhealthy products substantially increases their consumption-why else would aggressive and successful companies spend millions doing it? People are killed by this, and tobacco companies have therefore been excluded from many areas of sport. Questions have been raised about fast food and soft drink manufacturers. The "Coca-Cola Olympic City" is the abiding memory for many of the 1996 Olympic Games in Atlanta. Thought as a result to have been the only Games ever to have been run at a profit, it was sponsored by, and heavily promoted, Coca-Cola consumption. If healthy sponsors could be found, there is the potential to change not only patterns of exercise but diet too. This combination is the key to Western health.
Similarly there is the potential to influence social behaviour for good or ill. Team spirit and the sporting ethic lie at the heart of most performances. In contrast, the malignant behaviour of a minority of competitors who use performance enhancing drugs, and the behaviour of competitors on and off the pitch in some sports are bad examples.

There are other social, community, and environmental factors that more clearly act as hazards. Voiced as a concern in Athens, major events provide an opportunity for organised crime. Furthermore, the consequences to health of the associated drugs and prostitution are worrying. Terrorism too seeks mass media and spectacle. The incidents that unfolded on 5 September 1972 at the Munich Olympics testify to this. The current events in Iraq will place London at risk if the situation has not changed by 2012 . Major accidents such as occurred at Hillsborough and Heysel are rare, but immensely costly in terms of human tragedy. The mass travel of spectators hazards injury and the environment. To factor these issues into an equation on health gain is clearly relevant, although complex. They must also be balanced against the gains to world peace, bonding, and unity-the commonality that a Games brings.

Of course, simply to watch a sporting event brings no health gain at all. Indeed, an elegant English study of World Cup Football showed an increase in the number of hospital admissions and fatalities from myocardial infarction associated with key matches. ${ }^{4}$ The increase could not be accounted for by victims simply having an inevitable attack brought forward, as rates did not subsequently fall. Quite simply, watching national football kills measurable numbers of citizens. England lost the football, but no one has studied 1966 or the last Rugby World Cup to determine if winning is safer-certainly the current authors nearly died several times during the latter!

Thus, on the positive side of the health equation are to be found: a definite potential to increase levels of exercise and improve diet. On the negative side the list is longer: the potential for getting the dietary message wrong, injuries from increased sport, health risk of spectatorship at the venue and at home, risks of mass travel, and enhanced exposure to crime, disaster, and terrorism. Elements that might lie on either side of the equation are: the beneficial and malign influences on society of inappropriate role modelling, the prevailing politics, and the slings and arrows of inward investment. In summary, if gain is to be had from mass sporting events, it will be by focusing on the key issues of increasing the levels of spectator exercise, not sport, and by successfully encouraging healthy eating.

Elite sporting events associated with mass viewing need to be planned and executed so as to deliver on their potential for health gain and not leave a legacy of lost lives and blighted communities. If done well, the gains could be massive, but perhaps no more than the losses if executed poorly.

Although the benefits of exercise are irrefutable, the research published on the health legacy of major sporting events is scant. Referencing tends to be circular, and the markers of improved health are almost invariably indirect. It has been acknowledged that, although hard data to support the economic benefits and urban renewal are quite commonly generated, research into the health related impact is lacking. ${ }^{5}$ Very few hard data have been derived to support the widely professed assumptions that the effects of any given indicator are indeed beneficial to health. The fact that the Finns exercise so much more than the rest of us and yet have witnessed the same Olympics suggests that other influences on healthy living have been more at play, although this in itself does not mean that major sporting events cannot be used effectively.

It is to be hoped that the Olympic Games of 2012 will provide us with the opportunity to change an enthusiasm for these mass events built on beliefs and assumptions to one fashioned from hard fact. This would indeed be a legacy worthy of an Olympics.

Br J Sports Med 2005;39:882-883.

doi: $10.1136 / \mathrm{bjsm} .2005 .021006$

\section{Authors' affiliations \\ P J Hamlyn, Z L Hudson, Academic} Department of Sports and Exercise Medicine, Barts and The London School of Medicine and Dentistry, Queen Mary University of London

Correspondence to: Z L Hudson, Academic Department of Sports and Exercise Medicine, Barts and The London School of Medicine and Dentistry, Queen Mary University of London, London, UK; z.hudson@qmul.ac.uk

Competing interests: none declared

\section{REFERENCES}

1 Sport England. Athens Success attracts one in four to take up sport. http://www.sportengland.org/ news/press_releases/athens_success_inspires. htm (accessed 6 Apr 2005)

2 Department for Culture, Media and Sport (DCMS). Game plan: a strategy for delivering Government's sport and physical activity objectives. London: DCMS Strategy Unit, December, 2002.

3 Moore GE. The role of exercise prescription in chronic disease. Br J Sports Med 2004;38:6-7.

4 Carroll D, Ebrahim S, Tilling K, et al. Admissions for myocardial infarction and World Cup football: database survey. BMJ 2002;325: 1439-42.

5 Brown A, Massey J. Literature review: the impact of major sporting events. Manchester: Manchester Institute for Popular Culture, Manchester Metropolitan University, for UK Sport, June, 2001. 